\title{
Selection of Machining Parameters Using a Correlative Study of Cutting Tool Wear in High-Speed Turning of AISI 1045 Steel
}

\author{
Luis Wilfredo Hernández González ${ }^{1, *}$, Yassmin Seid Ahmed ${ }^{2}$,, Roberto Pérez Rodríguez $^{1}{ }^{10}$, \\ Patricia Del Carmen Zambrano Robledo ${ }^{3}$ (D) and Martha Patricia Guerrero Mata ${ }^{3}$ \\ 1 Study Center of CAD/CAM, Holguin University, Holguin CP 80100, Cuba; roberto.perez@uho.edu.cu \\ 2 McMaster Manufacturing Research Institute (MMRI), Department of Mechanical Engineering, \\ McMaster University, 1280 Main Street West, Hamilton, ON L8S 4L7, Canada; Seidahmy@mcmaster.ca \\ 3 Universidad Autónoma de Nuevo León-UANL, Facultad de Ingeniería Mecánica y Eléctrica, \\ División de estudios de Posgrados, San Nicolás de los Garza, Nuevo León 66455, Mexico; \\ patricia.zambranor@uanl.edu.mx (P.D.C.Z.R.); martha.guerreromt@uanl.edu.mx (M.P.G.M.) \\ * Correspondence: wilfredo@uho.edu.cu; Tel.: +53-24-482678
}

Received: 31 July 2018; Accepted: 7 October 2018; Published: 10 October 2018

check for updates

\begin{abstract}
The manufacturing industry aims to produce many high quality products efficiently at low cost, thereby motivating companies to use advanced manufacturing technologies. The use of high-speed machining is increasingly widespread; however, it lacks a deep-rooted knowledge base needed to facilitate implementation. In this paper, response surface methodology (RSM) has been applied to determine the optimum cutting conditions leading to minimum flank wear in high-speed dry turning on AISI 1045 steel. The mathematical models in terms of machining parameters were developed for flank wear prediction using RSM on the basis of experimental results. The high speed turning experiments were carried out with two coated carbide and a cermet inserts using AISI 1045 steel as work material at different cutting speeds and machining times. The models selected for optimization were validated through the Pareto principle. Results showed the GC4215 insert to be the most optimal option, because it did not reach the cutting tool life limit and could be used for the whole range of cutting parameters selected. To quantitatively evaluate the usefulness of the cutting tools, it was proposed the coefficient of use of the tools from the results of the contour graphs. The GC4215 insert showed 100\% effectiveness, followed by the GC4225 with $98.4 \%$, and finally, the CT5015 insert with $83 \%$.
\end{abstract}

Keywords: high speed turning; flank wear; response surface methodology; cutting speed; machining time; related factors; AISI 1045

\section{Introduction}

For a given cutting tool and workpiece material, a range of possible cutting parameters are provided. Cutting tool parameters are traditionally chosen according to handbooks and cutting tool data catalogs. The machinist selects the parameters within the ranges using well-known shop floor practices. These practices include:

(a) Higher cutting speeds increase surface roughness quality but decrease cutting tool life.

(b) Higher feed rates increase productivity as the material removal rate is increased.

(c) Higher feed rates decrease surface roughness quality.

(d) Higher feed rates decrease cutting tool life.

(e) A higher axial depth of cut increases productivity but decreases cutting tool life. 
(f) A very low axial depth of cut burns the workpiece surface and generates a low surface roughness quality and decreases cutting tool life.

According to the final goal of the machining process, the machinist selects the best cutting tool parameters combination [1]. To be competitive in the market, companies must create added value by rapidly producing high quality products and services, at a cost compatible with demand, while continuously striving to improve efficiency. Therefore, companies need to emphasize rapid product development together with short manufacturing cycles and delivery times [2]. In recent years, many companies have invested substantially in advanced manufacturing technologies. Foremost among these has been high-speed machining (HSM) technologies [3]. Although HSM is similar to traditional machining in conceptual terms, it differs in that it employs much higher cutting and feed rates, while reducing pass depth. High-speed machining (HSM), or more precisely high-speed cutting (HSC), has been of special interest to both the manufacturing and academia sectors for many years.

High-speed machining is a difficult term to define. There are four ways HSM can be distinguished. These are: cutting operation; work material; process stability; and cutting force or equivalently cutting energy orientation [4]. The most likely acceptable options are the cutting operation and work material. For instance, high-speed turning in plain carbon steel is considered when $\mathrm{v} \approx 600 \mathrm{~m} / \mathrm{min}$, however, this is a conventional cutting speed in aluminum cutting. It is also admitted when machining is performed between five to ten times the cutting speeds of the ones that are utilized as a conventional speed for each material.

However, high-speed cutting application has a negative detrimental impact by increasing tool wear. If a worn tool is not identified early enough, significant degradation of the workpiece quality can occur. Therefore, research on cutting tool wear is still of great interest, but experiments with newly developed tools in HSM are scarce [5].

Essel [6] studied the resultant cutting force, chip temperature and flank wear, in dry turning of the AISI 1045 and different alloyed AISI 1045 steels with an uncoated carbide at moderate cutting speeds. The cutting tools wear of carbides and ceramics, in the dry machining of AISI 1045 steel, were investigated by Tanaka et al. [7], using up to the intermediate cutting speed. Denkena et al. [8] determined changes in chip formation, cutting forces, and cutting temperature were due to a significant increase of cutting speed, in high speed turning of AISI 1045 steel with a coated insert. Lin [9] studied the cutting tool wear variation for different cutting speed and feed rate, in turning of AISI 1055 steel. This author did not include values regarding high speed cutting. Davies et al. [10] measured the temperature distributions during cutting of AISI 1045 steel, for a wide range of cutting parameters; however, did not include the cutting tool wear in their analysis. Iqbal et al. [11] presented an investigation into the tool-chip contact interface in high speed turning of AISI 1045 steel using uncoated cemented carbide tools. Later, the authors studied the effects of cutting speed on the tool rake face contact length, contact area, friction, chip compression ratio, and cutting force [12]. The authors did not investigate the variation of the chip compression ratio and contact length with undeformed chip thickness, in addition, cutting tool wear was not included [13]. Quan et al. [14] analyzed the effects of cutting speed on cutting heat flux and distribution of the cutting heat, in the dry turning of AISI 1045 steel with a P10 carbide insert. Stanford et al. [15] investigated the role of gaseous and liquid nitrogen as a cutting fluid when turning a plain carbon steel, and the implications of their use on tool wear, cutting force, as well as, cutting temperature. Diniz et al. [16] evaluated the effect of coolant pressure and flow rate on tool wear and tool life in turning, using up to the intermediate cutting speed. Adesta et al. [17] studied the effects of negative rake angle on flank wear and surface roughness, in turning of a plain carbon steel. However, because the authors carried out their experiments in high speed, they did not consider the machining time in their investigation. Ozlu et al. [18] performed cutting tests in turning of AISI 1050 steel, with inserts of different rake angles. Besides, the authors measured and calculated the values of friction coefficient, cutting forces, total contact length, and sticking contact length. Özel et al. [19] investigated the influence of insert geometry-both conventional and wiper corner geometry —on cutting forces and surface quality in the turning of AISI 1045 steel, using up to 
the intermediate cutting speed. Also, optimum tool life for a minimum energy of a turning process considering the energy budget in the manufacturing of a product was evaluated by Rajemi et al. [20]. Hernández et al. [21] studied the effect of the removed metal volume rate and cutting speed on the flank wear of two coated carbide and a cermet inserts, in high speed turning of AISI 1045 steel. The authors measured flank wear, but they did not include the correlative study. Stachurski et al. [22] reported an assessment of the effect of selected conditions on the value of the cutting force during turning of AISI 1045 steel with and without cutting fluid. Hernández et al. [23] analyzed the resultant cutting force evolution in high speed turning of AISI 1045 steel with two coated carbide and a cermet inserts, but the authors did not include the tool flank wear. Qasim et al. [24] presented an optimization of process parameters for high-speed machining of AISI 1045 steel, using several cutting tools, with the objective of reducing cutting forces and temperature. The principal investigations in high-speed turning of plain carbon steel are presented in Figure 1.

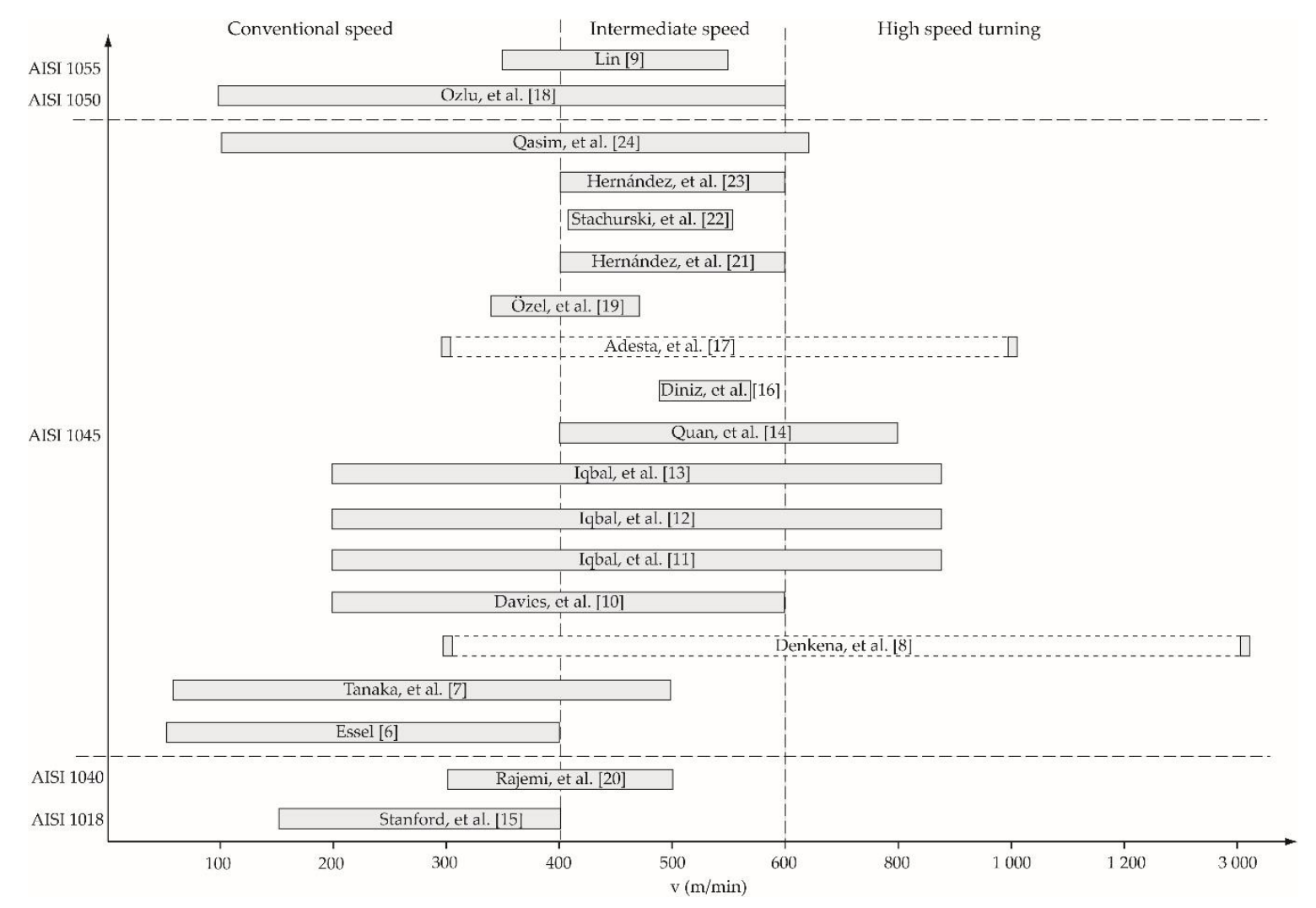

Figure 1. Main investigations in the high-speed turning of plain carbon steel.

Figure 1 shows there is a small amount of papers available for high-speed machining of carbon steel. However, there are no studies that have successfully performed a correlative analysis of flank wear of cutting tools with the cutting speed and machining time in high-speed turning of AISI 1045 steel. In the current study, the influences of tool material, cutting speed, and machining time on flank wear were examined. This research substantially reduced the number of complex and expensive experiments conducted on machining centers by determining the optimal tuning parameters needed to obtain lower flank wear in high-speed dry turning of AISI 1045 steel. It is possible to apply this optimization technique to different applications in the manufacturing industry to obtain optimal process parameters to reduce manufacturing costs and processing time, and thereby productivity. Therefore, this study will be useful for future applications in both manufacturing industry and the academic environment. 


\section{Materials and Methods}

\subsection{Flank Wear Criterion for Cutting Tool Life Definition}

According to ANSI/ASME B94.55M [25], the tool life criteria for carbide and ceramic inserts is $V_{\mathrm{BB}}=300 \mu \mathrm{m}$. Recent studies conducted by Saï et al. [26] in high-speed turning of AISI 4340 steel suggested the selection of the wear parameter is dependent on cutting speed. Besides, recommendations used in industrial practice for finishing operations is up to $V_{B B}=250 \mu \mathrm{m}$ for coated carbide inserts and $\mathrm{V}_{\mathrm{BB}}=200 \mu \mathrm{m}$ for ceramics inserts [27]. In this study, $\mathrm{V}_{\mathrm{BB}}=250 \mu \mathrm{m}$ is chosen based on results in the literature, and it is concerning a finishing operation at moderate, intermediate and high cutting speed.

\subsection{Sample Characteristics}

In the current study, the AISI-SAE 1045 carbon steel was selected as work material, in hot rolled condition, as it is widely used in the manufacturing of parts for metal mechanics and the automobile industry. This steel is considered critic standard to manufacture machine parts. The composition of AISI 1045 steel is perlite-ferrite at $50 \%$, with a medium carbon percent. This is the maximum percentage for its group, leading to improved mechanical properties, at the cost of making machinability more difficult. The chemical composition and mechanical properties of AISI 1045 are given in Table 1.

Table 1. Chemical composition of AISI 1045.

\begin{tabular}{cccccc}
\hline Elements & $\begin{array}{c}\text { Chemical } \\
\text { Composition \% }\end{array}$ & $\begin{array}{c}\text { Proof Strength } \\
(\mathbf{0 . 2 \%} \text { Yield) MPa }\end{array}$ & $\begin{array}{c}\text { Tensile } \\
\text { Strength MPa }\end{array}$ & Elongation \% & HRC Hardness \\
\hline $\mathrm{C}$ & 0.45 & & & \\
$\mathrm{Si}$ & 0.15 & & & & \\
$\mathrm{Mn}$ & 0.71 & 300 & 570 & & \\
$\mathrm{P}$ & 0.036 & & & \\
$\mathrm{~S}$ & 0.007 & & & \\
$\mathrm{Cr}$ & 0.122 & & & \\
$\mathrm{Ni}$ & 0.024 & & & \\
$\mathrm{Al}$ & 0.035 & & & \\
\hline
\end{tabular}

The microstructure and grain size were examined on the complete transversal section of workpiece, using an optical microscope (Nikon Epiphot). The grain size was thin $(8 \mu \mathrm{m})$, which impacted the machinability negatively as it increased the necessary cutting forces to break the attraction forces of grains. The hardness of the sample has been measured on the complete cross section, using five randomly selected specimens which belong to the diagonal of a disk of a cylindrical specimen, using a micro hardness tester (Shimadzu). The average hardness was $271 \mathrm{HV}$, and its conversion according to standard ASTM E 140-97 [28], is 258 HB hardness.

\subsection{Characteristics of Inserts}

Two coated carbide tools (CVD) GC4215-P15 and GC4225-P25 were compared during cutting tests as well as the uncoated cermet CT5015-P10 to determine flank wear. All the tested tools were manufactured by Sandvik. The tool holder had the designation SCLCR/L 2020K 12. The cutting tool characteristics are given in Table 2. After the tests, the cutting tools were analyzed using the JEOL scanning electron microscope (SEM). Every cutting edge of the cutting tools were previously inspected using the NIKON EPIPHOT optical microscope, with a magnification of 50x to reveal any visual defects. All the cutting edges were observed to be in good state.

The surface roughness of the cutting tools on the flank and face surfaces were measured using a Surface Measuring Machine (Carl Zeiss). For both surfaces, the average surface roughness (Ra) was less than $0.25 \mu \mathrm{m}$, which is in accordance with the standard ANSI/ASME B94.55M [25]. Besides, the inserts hardness was measured in different points on the face surface with the SHIMADZU 
microhardness tester, the average hardness was: 2046 HV for insert CT5015, 1631 HV for insert GC4215 and $1789 \mathrm{HV}$ for insert GC4225.

Table 2. Characteristics of inserts.

\begin{tabular}{cccccccccc}
\hline \multirow{2}{*}{ Insert } & \multicolumn{4}{c}{ Coatings } & \multicolumn{5}{c}{ Substrates } \\
\cline { 2 - 10 } & $\begin{array}{c}\text { First } \\
\text { Layer }\end{array}$ & $\begin{array}{c}\text { Second } \\
\text { Layer }\end{array}$ & $\begin{array}{c}\text { Third } \\
\text { Layer }\end{array}$ & $\begin{array}{c}\text { Width } \\
(\mu \mathrm{m})\end{array}$ & $\mathbf{W}$ & $\mathbf{T i}$ & $\mathbf{C o}$ & $\mathbf{N b}$ & $\mathbf{A l}_{2} \mathbf{O}_{3}$ \\
\hline CT5015-P10 & - & - & - & - & 20.68 & 47.2 & 17.71 & 8.71 & 5.7 \\
\hline GC4215-P15 & $\mathrm{TiN}$ & $\mathrm{Al}_{2} \mathrm{O}_{3}$ & $\mathrm{Ti}(\mathrm{N}, \mathrm{C})$ & 15 & 96.19 & 1.44 & 2.38 & - & - \\
\hline $\mathrm{GC} 4225-\mathrm{P} 25$ & $\mathrm{Ti}(\mathrm{C}, \mathrm{N})$ & $\mathrm{Al}_{2} \mathrm{O}_{3}$ & - & 10 & 94.77 & 2.1 & 3.13 & - & - \\
\hline
\end{tabular}

\subsection{Experimental Setup and Factorial Design of the Investigation}

This investigation is focused on the study of flank wear of three inserts with three levels of cutting speeds and five levels of machining times. Furthermore, two replicas for the acquisition of information have been made. In total, there were 90 tests. The experiments have been conducted on 10 solid cylindrical workpieces with an initial diameter of $80 \mathrm{~mm}$ and a length of $300 \mathrm{~mm}$. The depth of cut $(\mathrm{a}=0.5 \mathrm{~mm})$ and feed rate $(\mathrm{f}=0.1 \mathrm{~mm} / \mathrm{r})$ were kept constant. The cutting conditions used in the experiments were selected according to the review of the scientific literature [7-24]. These are described in Table 3.

Table 3. Cutting conditions of investigation.

\begin{tabular}{|c|c|c|}
\hline Variable & Type of Variable & Measure \\
\hline Flank wear & Dependent & Flank wear $(\mu \mathrm{m})$ \\
\hline Material of cutting tool & Independent & $\begin{array}{l}\text { Uncoated Cermet CT5015 (ISO P10) and coated } \\
\text { carbides GC4215 (ISO P15) y GC4225 (ISO P25) }\end{array}$ \\
\hline Cutting speed & Independent & $(400,500$ and 600$) \mathrm{m} / \mathrm{min}$ \\
\hline Machining time & Independent & $\begin{array}{l}\text { Machining time }(2 ; 4 ; 6 ; 8 \text { and } 10) \mathrm{min} \text { for } 400 \mathrm{~m} / \mathrm{min} \text {, } \\
(1 ; 2 ; 3 ; 4 \text { and } 5) \mathrm{min} \text { for } 500 \mathrm{~m} / \mathrm{min} \text { and }(0.6 ; 1.2 ; 2 ; 3 \\
\text { and } 4) \mathrm{min} \text { for } 600 \mathrm{~m} / \mathrm{min}\end{array}$ \\
\hline
\end{tabular}

When a number of measurements of a same parameter are repeated, a typical or suspicious value may be obtained. There are many ways to determine if a set of data are outliers. In this study, two methods were used: determination by empirical rule or by percentiles.

The first method is adequate if the data is consistent with the properties of the normal distribution curve. For numerous measurements of a magnitude, the average $(\bar{x})$ and standard deviation (S) are calculated. Then, the interval is set up (Equation (1)) for a given confidence level, and all the values that are left out of the aforementioned range are eliminated. Finally, necessary calculations are made to express the final result, without the uncommon values.

$$
\bar{x} \pm \mathrm{tS}
$$

where $t$ is interval that contain to $\mu$. For $95 \%$ of confidence level $t=1.96$.

The second method to detect outliers has a graphical version: it is called a boxplot, or box and whisker plot [29].

\section{Experimental Results, Analysis, and Discussion}

This section discusses the selection of cutting speed and machining time based on cutting tool wear. Cutting tool wear is one of the most important factors among several aspects of the machining process. When flank wear increases, the surface roughness, stability of machining, operation cost, and the dimensional and geometric tolerances, are negatively affected. The selection of suitable cutting 
parameters is an important task for minimizing the cutting tool wear in high-speed machining with the current cutting tool materials.

\subsection{Flank Wear Analysis in High-Speed Turning}

Figure 2 shows the wear mechanisms associated with machining AISI 1045 steel with CT5015-P10, GC4215-P15, and GC4225-P25 inserts. As shown for all used cutting inserts, there are areas where material adhered to the surface of the tool. Areas which have a rough aspect on their cutting edge are characteristic of the adhesive wear mechanism. Adhesive wear frequently occurs when there is chemical affinity between the tool and the workpiece material. In this case, intensive adhesion leads to the formation of intensive built-up edge (BUE) at the tool-chip interface which leads to mass loss or mass dislocation. BUE grows throughout the cutting process and periodically breaks off, creating cracks and damage on the tool surface and eventually causes cutting edge break-out [10]. As shown, chipping wear is observed in CT5015-P10 and GC4225-P25 inserts, which indicates mechanical fatigue caused by high BUE formation as the main reason for chipping wear.

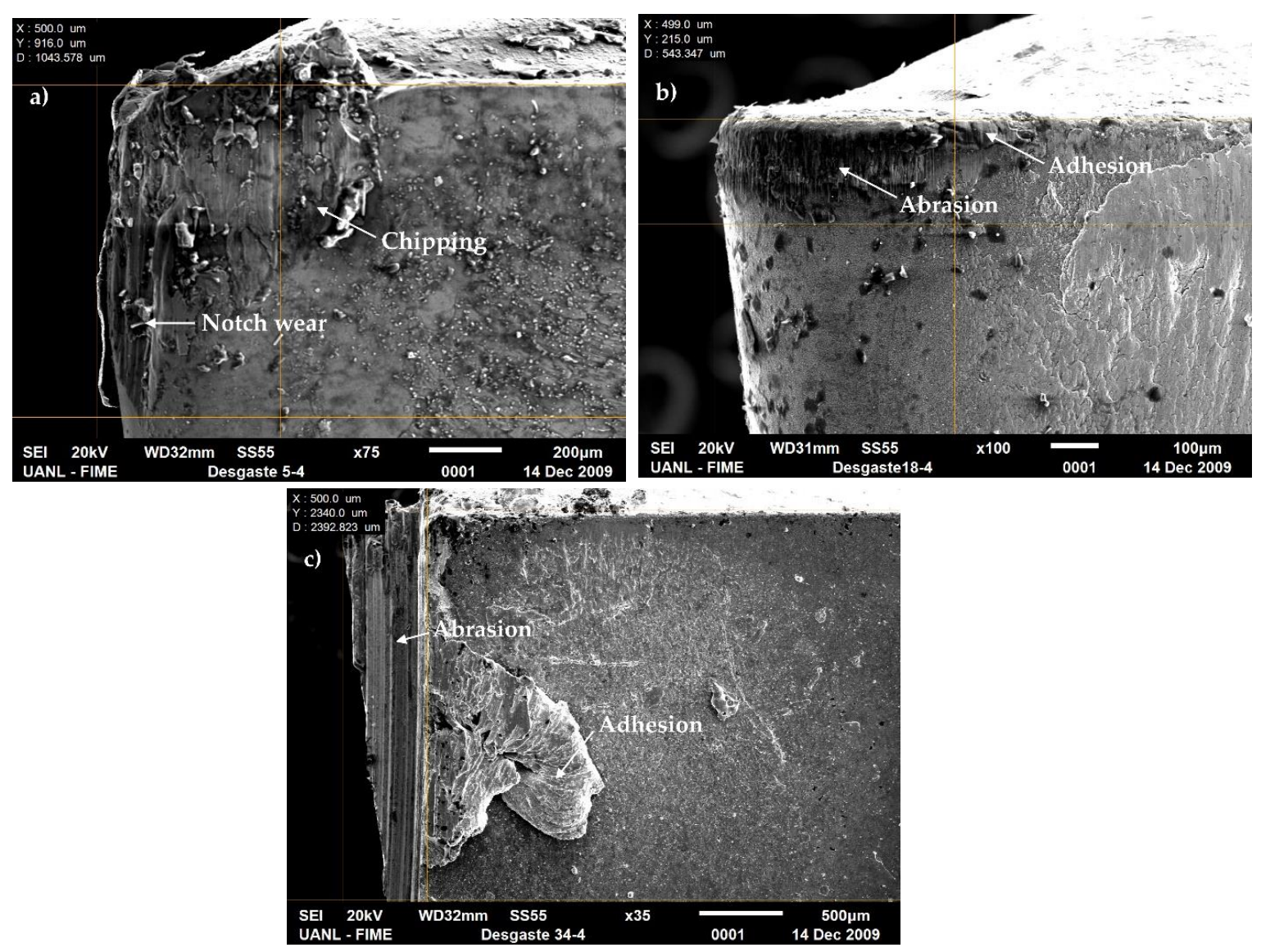

Figure 2. Flank wear for $\mathrm{v}=600 \mathrm{~m} / \mathrm{min}$ and $\mathrm{T}=4 \mathrm{~min}$, (a) for CT5015-P10 insert, (b) for GC4215-P15 insert and (c) for GC4225-P25 insert.

All used cutting tools also showed parallel lines in the direction of sliding action, indicating abrasive wear. Abrasive wear occurs as a result of grains, which are broken off during the turning process and restricted between the chip and the tool, scratching on the flank face of the tool. Also, Figure 2a (CT5015-P10) and Figure 2c (GC4225-P25) show notch wear produced on the flank face of the insert. Notch wear mainly occurs due to the high ductility of AISI 1045 steel, which formed a very hard burr at the end of the depth of the cut. This burr leads to removal of the coating and generates notch wear. As indicated, the rate of notch wear was higher than the rate of flank wear because of the high cutting temperature, see Figure 2a,c. This type of wear generally occurs in regions exposed to 
the atmosphere. Under certain conditions, oxygen could react with cutting tools resulting in a high percentage indicator for oxygen thereby causing noticeable notch wear on the cutting tools.

It is generally considered that the wear of the cutting tool is a result of mechanical (thermo-dynamic wear, due to thermally-loaded motion, i.e., abrasion, adhesion) and chemical (thermo-chemical wear, where elevated temperatures enhance chemical processes, i.e., diffusion, oxidation) interactions between the tool and workpiece [30]. The newly developed tool materials provide the possibility of raising cutting speeds, which significantly increases the cutting temperature. Therefore, the appearance of the thermo-chemical wear becomes more evident, especially when the speeds move into the high-speed-cutting range. Here, the cutting edge locally heats to $1000{ }^{\circ} \mathrm{C}$ or more, which enhances the diffusion and oxidation processes [31,32].

Additionally, the material hardness of cutting tools decreased at high cutting temperatures, favoring abrasive wear. For carbide cutting tools, the high cutting temperatures also stimulated diffusion, adhesion, plastic deformation and other mechanisms [33-35].

\subsection{Analysis of the Design}

\section{Determination of Outliers}

It was first determined whether the values of the flank wear satisfied the characteristics of the normal distribution, to decide which method to use in determining the existence of unusual values. The normality test was performed using the Bias and Kurtosis standardized. STATGRAPHICS software was used for this purpose. Statistical values outside the rank from -2 to +2 indicated significant deviations from normality. These statistical values of the cutting tools are presented in Table 4 .

Table 4. Bias and Kurtosis standardized of the cutting tool wear.

\begin{tabular}{ccc}
\hline Cutting Tool & Bias Standardized & Kurtosis Standardized \\
\hline CT5015 & 10.817 & 28.184 \\
GC4215 & 0.442 & -0.535 \\
GC4225 & 8.366 & 14.968 \\
\hline
\end{tabular}

The CT5015 and GC4225 inserts indicate significant deviations of normality. However, the GC4215 insert fulfills the properties of a normal distribution. So, the atypical values for the CT5015 and GC4225 inserts, are determined by percentiles, while, the unusual values for the GC4215 insert are calculated using the empirical rule. The outliers of the cutting tool wear are presented in Table 5. Consequently, the outliers are eliminated.

Table 5. Outliers of the cutting tool wear.

\begin{tabular}{cccc}
\hline Cutting Tool & Average & Standard Deviation & Outliers \\
\hline CT5015 & 0.217 & 0.1372 & $0.916 ; 0.307$ \\
GC4215 & 0.130 & 0.036 & 0.215 \\
GC4225 & 0.298 & 0.488 & $0.341 ; 1.793 ; 2.34$ \\
\hline
\end{tabular}

The diagram of Pareto was used to evaluate the effects of the variable independents and to determine which ones influence the flank wear of the cutting tools. A proper software shows the absolute value of the effects in Pareto's diagram. Figures 3-5 display graphical representations of the effects on the flank wear. The effects located to the right of the reference line are significant.

Figure 3 shows Pareto's graphic of the effect of variables in significance order for the CT5015-P10 insert. The results show that factors (machining time, cutting speed and their interaction), influenced the dependent variable (cutting tool wear). Additionally, the machining time was the most significant variable. Figure 4 shows Pareto's graphic of the effect of variables in significance order for the GC4215-P15 insert. 
Figure 5 displays Pareto's graphic of the effect of variables in order of significance for the GC4225-P25 insert. Again, the factors (machining time, cutting speed and their interaction), all meaningfully impacted the cutting tool wear and the machining time was the most significant variable. The tool flank wear will increase with cutting time [4] and cutting speed [36], while cutting speed has more effect on tool life than feed rate [6]. Essel [6] did not perform a correlative analysis of the cutting tool wear with the cutting speed and machining time, also, their study was developed at conventional speeds. Similarly [20], the most significant factor for flank wear was cutting speed, but authors did not perform a correlative analysis either.

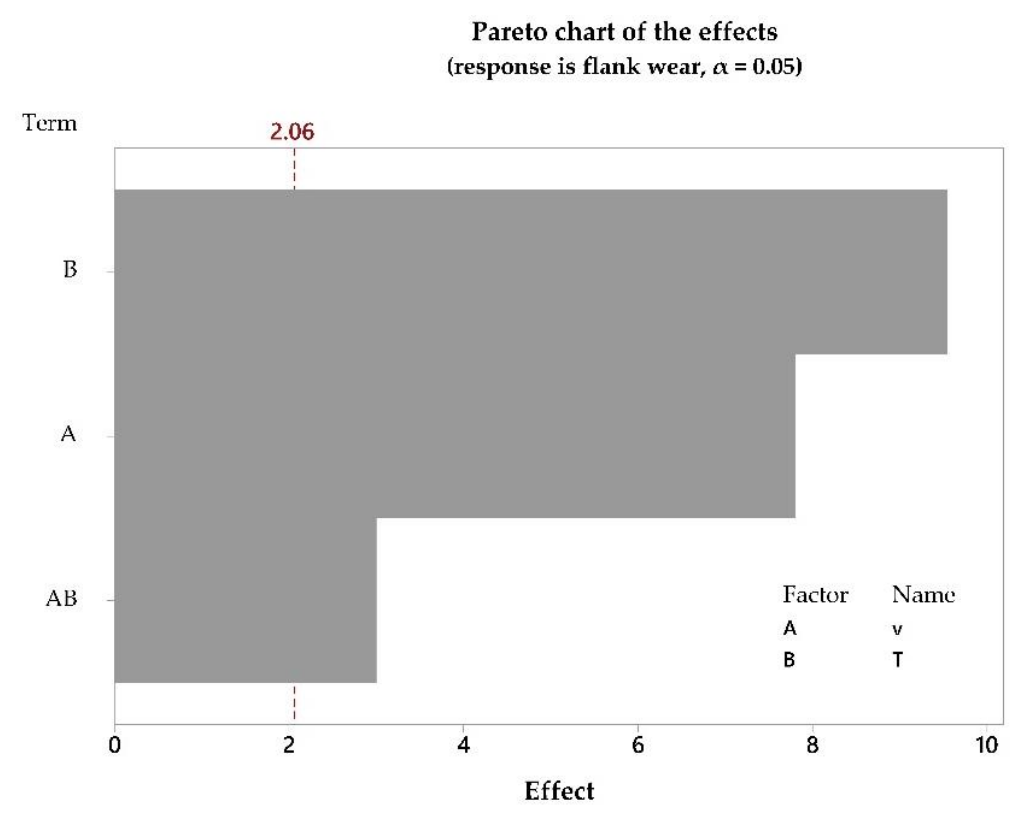

Figure 3. Pareto graphic of variable effects on flank wear, for the CT5015-P10 insert.

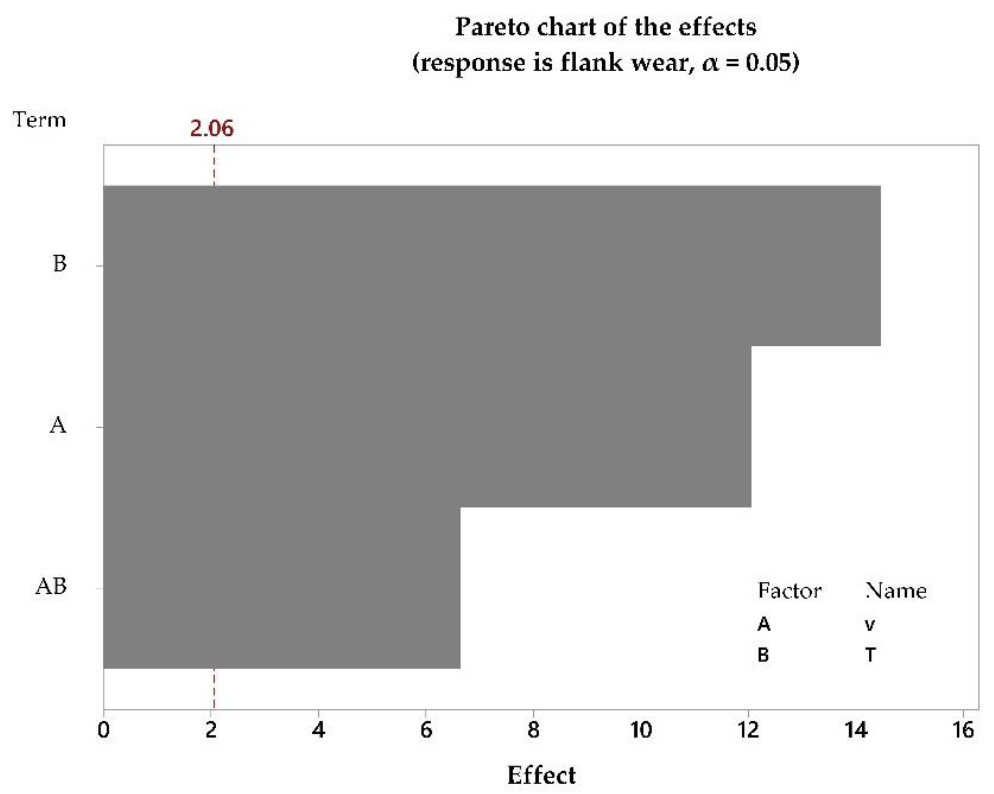

Figure 4. Pareto graphic of variable effects on flank wear, for the GC4215-P15 insert. 


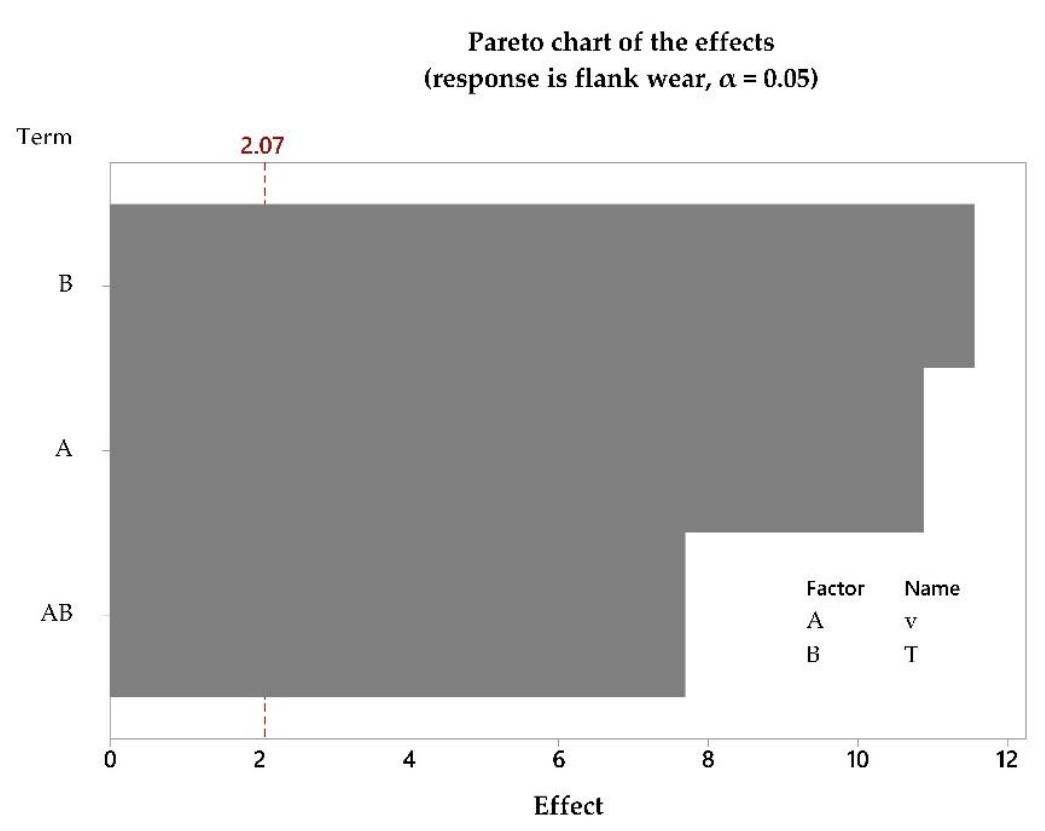

Figure 5. Pareto graphic of variable effects on flank wear, for the GC4225-P25 insert.

3.3. ContourPlot for the Relation between the Input Factors and Flank Wear of the Cutting Tools

To determine whether the variables $(\mathrm{T}, \mathrm{v}$, and $\mathrm{w})$ are related, the following conditions must be met:

- The coefficient of determination $\left(\mathrm{R}^{2}\right)$ must be at least greater than $50 \%$.

- The $p$-value of the analysis of variance of the model is less than 0.05 (there is a statistically significant relationship between the variables with a confidence level at $95.0 \%$ ).

- The $p$-value (the probability of $\mathrm{t}$ ) of the independent variables should be less than 0.05 (statistically significant with a confidence level at 95.0\%).

- The basic assumptions of regression analysis [37].

The coefficient of determination $\left(\mathrm{R}^{2}\right)$ and $p$-value of the analysis of variance of the models are presented in Table 6 . The coefficient of determination is greater than $50 \%$, and the $p$-values are less than 0.05 .

Table 6. Coefficient of determination and $p$-value of the analysis of variance of the models.

\begin{tabular}{cccc}
\hline Cutting Tool & Model & $\mathbf{R}^{2}$ & $p$ \\
\hline CT5015 & $\mathrm{w}=0.000292 \cdot \mathrm{v}+0.012412 \cdot \mathrm{T}$ & 0.745 & 0.000 \\
GC4215 & $\mathrm{w}=-0.0960164+0.0137316 \cdot \mathrm{T}+0.000347288 \cdot \mathrm{v}$ & 0.720 & 0.000 \\
GC4225 & $\mathrm{w}=0.000380 \cdot \mathrm{v}-0.078377 / \mathrm{T}+0.004208 \cdot \mathrm{T}$ & 0.668 & 0.000 \\
\hline
\end{tabular}

The $p$-value (the probability of $\mathrm{t}$ ) of the independent variables were presented in Pareto's diagram, Figures $3-5$. The factors are statistically significant for a confidence level of $95.0 \%$.

Finally, the basic assumptions of regression analysis were verified. The EViews software was used for this purpose.

From the obtained histogram, the assumptions of normality and the null mean are verified. The critical region was: Probability (Jarque-Bera) $<\alpha(0.05 \%$ significance level).

The Breusch-Godfrey test was used to verify the non-autocorrelation assumption. The critical region was: Probability $\left(\mathrm{n} \cdot \mathrm{R}^{2}\right)<\alpha$.

To confirm compliance with the homoscedasticity assumption, the assumption was verified with the non-crossover regression terms. Critical region: Probability $\left(n \cdot R^{2}\right)<\alpha$. The results of the basic assumptions of regression analysis are presented in Table 7. 
Table 7. Results of the basic assumptions of regression analysis.

\begin{tabular}{ccccc}
\hline Cutting Tool & Prob. (Jarque-Bera) & Mean & $\begin{array}{c}\text { Prob. (n· } \mathbf{R}^{\mathbf{2}} \text { ) } \\
\text { Non-autocorrelation }\end{array}$ & $\begin{array}{c}\text { Prob. }\left(\mathbf{n} \cdot \mathbf{R}^{\mathbf{2}} \text { ) }\right. \\
\text { Homoscedasticity }\end{array}$ \\
\hline CT5015 & 0.4223 & $-0.456 \times 10^{-3}$ & 0.1623 & 0.4198 \\
GC4215 & 0.5447 & $0.18 \times 10^{-19}$ & 0.1608 & 0.3434 \\
GC4225 & 0.1174 & $-0.18 \times 10^{-3}$ & 0.7491 & 0.3684 \\
\hline
\end{tabular}

The results of the basic assumptions of regression analysis for the CT5015 insert are the following: Decision: $0.4223>0.05$; therefore, the normality assumption is fulfilled.

The mean is equal to $-0.456 \times 10^{-3}$ and the assumption of zero mean is fulfilled.

Decision: $0.1623>0.05$. Therefore, the assumption of non-autocorrelation is fulfilled.

Decision: $0.4198>0.05$. Therefore, the assumption of homoscedasticity is fulfilled. Consequently, the conditions are fulfilled to state that, the variables machining time, cutting speed and flank wear are related.

Figure 6 displays the contour plot for the relation between the input factors and flank wear of the CT5015 insert. This cutting tool material reached high flank wear $(\mathrm{w}=0.29 \mathrm{~mm})$. However, this insert is recommended $(\mathrm{w}<0.25 \mathrm{~mm})$ for the area of $\mathrm{T} \leq 6 \mathrm{~min}$ and all cutting speed values, as well as for $\mathrm{v} \leq 440 \mathrm{~m} / \mathrm{min}$ and all ranges of T. Figure 7 shows the contour plot for GC4215 insert. This insert is recommended to be used for the whole range of cutting parameters selected because it did not reach the cutting tool life limit. Figure 8 shows the contour plot for GC4225 insert. This insert could be utilized for the whole range of machining time and $\mathrm{v} \leq 570 \mathrm{~m} / \mathrm{min}$, as well as, for $\mathrm{T}<8 \mathrm{~min}$ and $\mathrm{v}>570 \mathrm{~m} / \mathrm{min}$.

Results show the optimal insert is GC4215 (ISO P15), then GC4225 (ISO P25). The least productive insert was CT5015 (ISO P10). The GC4215 (ISO P15) insert did not reach the cutting life limit; therefore, it can be used for the whole range of cutting parameters selected.

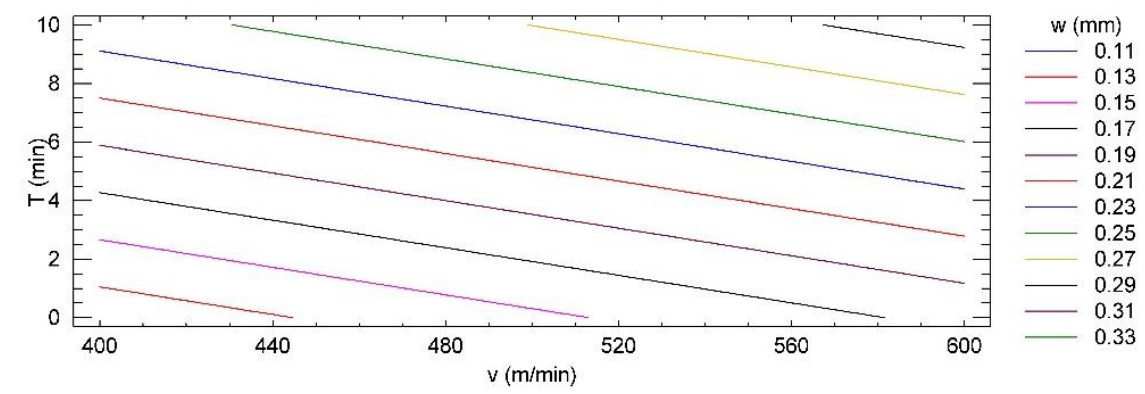

Figure 6. Contour plot for the relation between the input factors (machining time-cutting speed) and flank wear of CT5015 (ISO P15) insert.

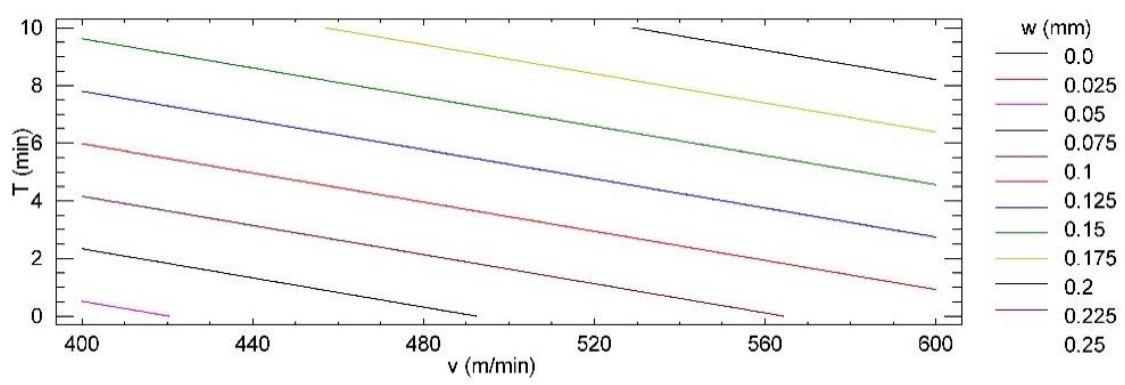

Figure 7. Contour plot for the relation between the input factors (machining time-cutting speed) and flank wear of GC4215 (ISO P15) insert. 


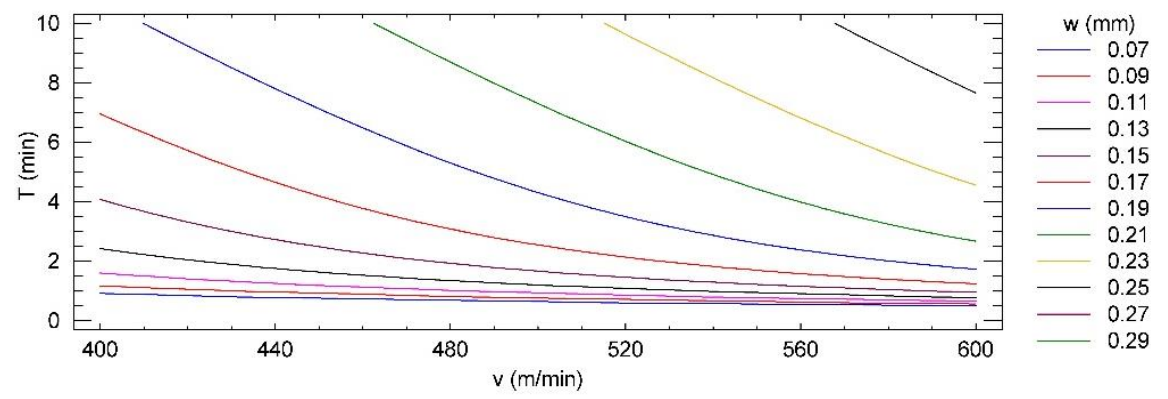

Figure 8. Contour plot for the relation between the input factors (machining time-cutting speed) and flank wear of GC4225 insert.

In summary, after the dry turning of AISI 1045 steel with different cutting tool materials, it is possible to see that, in high-speed machining areas $(\mathrm{v}=600 \mathrm{~m} / \mathrm{min}$ ), the tool life of the CT5015 (ISO P10) and GC4225 (ISO P25) inserts are easily affected, leading to excessive tool wear during machining operations. The developed tool materials provide the possibility of raising the cutting speeds, which significantly increases the cutting temperature $[13,29,34]$. Also, the high temperatures encountered in high-speed machining are a result of a greater amount of heat being generated over a small area and in a short contact time [38].

The results of the study showed GC4215 insert to be the optimal choice for the whole range of cutting parameters. A possible reason for this finding was that the external coating $(\mathrm{Ti}(\mathrm{N}, \mathrm{C}))$ provided greater toughness and abrasive wear resistance, thereby providing a better resistance to flank wear. Additionally, the $\mathrm{Al}_{2} \mathrm{O}_{3}$ coating contributed with the effect of a thermal barrier. Finally, the TiN coating supplied a low coefficient of friction, toughness, which acted as a thermal barrier, and produced a strong adhesion to the substratum. Therefore, the GC4215 insert was in a better condition to face the severe conditions of high-speed turning. Additionally, there is not always a linear relationship between the input parameters and flank wear, and it required a higher number of replications to get a more realistic result.

\subsection{Determination of the Coefficient of Use of the Inserts}

It is proposed that to quantitatively evaluate the usefulness of the cutting tools through flank wear, the coefficient use of the tools from the results of the contour graphs are analyzed.

First, the total region of use of the tools $\left(A_{t}\right)$ is calculated, according to Equation (2)

$$
\mathrm{A}_{\mathrm{t}}=\mathrm{v} \mathrm{T}
$$

Then, the region of the contour plot that does not meet the condition of $\mathrm{w}<0.25 \mathrm{~mm}\left(\mathrm{~A}_{\mathrm{nu}}\right)$, is determined. Finally, the coefficient of use of the cutting tool $\left(C_{u}\right)$ is calculated from Equation (3).

$$
C_{u}=\frac{A_{t}-A_{n u}}{A_{t}} 100 \%
$$

The coefficient of use of the cutting tools is presented in Table 8. The GC4215-P15 insert showed the best result, followed by the GC4225-P25 with 98.4\%, finally, the CT5015-P10 insert with 83\%.

Table 8. Coefficient of use of the cutting tools.

\begin{tabular}{cc}
\hline Cutting Tool & $\mathbf{C}_{\mathbf{u}}(\%)$ \\
\hline CT5015-P10 & 83 \\
GC4215-P15 & 100 \\
GC4225-P25 & 98.4 \\
\hline
\end{tabular}


Future studies are planned to utilize the techniques of Artificial Intelligence for the selection of optimum machining conditions and compare it with the results of this investigation.

\section{Conclusions}

1. The high-speed dry turning of AISI 1045 steel was performed in order to determine the minimum flank wear area of three cutting tool materials, using the contour graph of the relationship between machining time and cutting speed.

2. For high cutting speeds, insert CT5015-P10 exhibited excessive wear revealing abrasion, adhesion, plastic deformation, and chipping. Insert GC4225-P25 also showed significant abrasion, adhesion, plastic deformation and cutting edge fracture, while insert GC4215-P15 showed abrasion and adhesion followed by plastic deformation and chipping.

3. The models selected for optimization have been validated through the Pareto principle. The Pareto graph showed that the variables (cutting speed, machining time and their interaction), influenced the flank wear of the CT5015-P10, GC4215-P15 and GC4225-P25 inserts. Additionally, the machining time was the most significant factor on flank wear of the cutting tools.

4. The three coated GC4215 cutting tool was the best option, since it did not reach the limit of useful life and can be used for the entire range of cutting parameters selected.

5. The CT5015 insert is recommended to be used $(\mathrm{w}<0.25 \mathrm{~mm})$ for the area of $\mathrm{T} \leq 6 \mathrm{~min}$ and all value of cutting speed, as well as, for $\mathrm{v} \leq 440 \mathrm{~m} / \mathrm{min}$ and all range of machining time. The GC4225 insert could be utilized for the whole range of machining time and $\mathrm{v} \leq 570 \mathrm{~m} / \mathrm{min}$, as well as, for $\mathrm{T}<8 \mathrm{~min}$ and $\mathrm{v}>570 \mathrm{~m} / \mathrm{min}$.

6. In order to quantitatively evaluate the usefulness of the cutting tools through flank wear, it was proposed to analyze the coefficient of use of the tools from the results of the contour graphs, taking into account the criterion of the end of useful life. The GC4215-P15 insert showed $100 \%$ of effectiveness, followed by the GC4225-P25 with 98.4\%, finally, the CT5015-P10 insert 83\%.

Author Contributions: L.W.H.G. performed the cutting experiment and wrote the paper. Y.S.A. reviewed and edited the paper. R.P.R. performed the statistical analysis. P.D.C.Z.R. is coordinator of the investigation, as well as, designed the machining experiment. M.P.G.M. performed the metallographic, hardness and SEM studies, besides, planned experimental procedure. All authors have read and approved the final manuscript.

Acknowledgments: The authors would like to thank PRONABES for providing a postgraduate research scholarship at the Universidad Autónoma de Nuevo León (UANL) in México. We are also grateful for the financial support from the Centro de Desarrollo, Investigación e Innovación Tecnológica (UANL) in Monterrey and the Instituto Tecnológico y de Estudios Superiores de Monterrey (México, Campus of Monterrey), for all the facilities to develop this research. We also want to thank the Department of Mechanical Engineering of the University of Holguín, for the offered support.

Conflicts of Interest: The authors declare no conflict of interest.

\section{References}

1. Abellan, J.V.; Romero, F.; Siller, H.R.; Estruch, A.; Vila, C. Adaptive control optimization of cutting parameters for high quality machining operations based on neural networks and search algorithms. In Advances in Robotics, Automation and Control, 1st ed.; Arámburo, J., Ramírez, A., Eds.; I-Tech: Vienna, Austria, 2008; Volume 23, pp. 1-18, ISBN 78-953-7619-16-9.

2. Alberti, M.; Ciurana, J.; Rodríguez, C.; Özel, T. Design of a decision support system for machine tool selection based on machine characteristics and performance tests. J. Intell. Manuf. 2011, 22, 263-277. [CrossRef]

3. Aspinwall, D.K.; Dewes, R.C.; Burrows, J.M.; Paul, M.A. Hybrid High speed machining (HSM): System design and experimental results for grinding/HSM and EDM/HSM. Ann. CIRP Manuf. Technol. 2001, 50, 145-148. [CrossRef]

4. Grzesik, W. High Speed Machining. In Advanced Machining Processes of Metallic Materials. Theory, Modelling and Applications, 1st ed.; Grzesik, W., Ed.; Elsevier: Amsterdam, The Netherlands, 2008; Volume 1, pp. 213-225, ISBN 978-0-08-044534-2. 
5. Saï, W.B. An investigation of tool wear in high-speed turning of AISI 4340 steel. Int. J. Adv. Manuf. Technol. 2005, 26, 330-334. [CrossRef]

6. Essel, I. Machinability Enhancement of Non-Leaded Free Cutting Steels. Ph.D. Thesis, Rheinisch-Westfälischen Technischen Hochschule, Aachen, Germany, 22 May 2006.

7. Tanaka, R.; Yamane, Y.; Sekiya, K.; Narutaki, N.; Shiraga, T. Machinability of BN free-machining steel in turning. Int. J. Mach. Tools Manuf. 2007, 47, 1971-1977. [CrossRef]

8. Denkena, B.; Ben Amor, R.; de León-García, L.; Dege, J. Material specific definition of the high speed cutting range. Int. J. Mach. Mach. Mater. 2007, 2, 176-185. [CrossRef]

9. Lin, W.S. The reliability analysis of cutting tools in the HSM processes. Arch. Mater. Sci. Eng. 2008, 30, 97-100. [CrossRef]

10. Davies, M.A.; Cooke, A.L.; Larsen, E.R. High bandwidth thermal microscopy of machining AISI 1045 steel. Ann. CIRP 2005, 54, 63-66. [CrossRef]

11. Iqbal, S.A.; Mativenga, P.T.; Sheikh, M.A. Characterization of machining of AISI 1045 steel over a wide range of cutting speeds. Part 1: Investigation of contact phenomena. Proc. Inst. Mech. Eng. Part B 2007, 221, 909-916. [CrossRef]

12. Iqbal, S.A.; Mativenga, P.T.; Sheikh, M.A. Contact length prediction: Mathematical models and effect of friction schemes on FEM simulation for conventional to HSM of AISI 1045 steel. Int. J. Mach. Mach. Mater. 2008, 3, 18-33. [CrossRef]

13. Iqbal, S.A.; Mativenga, P.T.; Sheikh, M.A. A comparative study of the tool-chip contact length in turning of two engineering alloys for a wide range of cutting speeds. Int. J. Adv. Manuf. Technol. 2009, 42, 30-40. [CrossRef]

14. Quan, Y.; He, Z.; Dou, Y. Cutting heat dissipation in high-speed machining of carbon steel based on the calorimetric method. Front. Mech. Eng. China 2008, 3, 175-179. [CrossRef]

15. Stanford, M.; Lister, P.M.; Morgan, C.; Kibble, K.A. Investigation into the use of gaseous and liquid nitrogen as a cutting fluid when turning BS 970-80A15 (En32b) plain carbon steel using WC-Co uncoated tooling. J. Mater. Process. Technol. 2009, 209, 961-972. [CrossRef]

16. Diniz, A.E.; Micaroni, R.; Hassui, A. Evaluating the effect of coolant pressure and flow rate on tool wear and tool life in the steel turning operation. Int. J. Adv. Manuf. Technol. 2010, 50, 1125-1133. [CrossRef]

17. Adesta, E.T.; Riza, M.; Hazza, M.; Agusman, D.; Rosehan, R. Tool wear and surface finish investigation in high speed turning using cermet insert by applying negative rake angles. Eur. J. Sci. Res. 2009, 38, 180-188.

18. Ozlu, E.; Molinari, A.; Budak, E. Two-zone analytical contact model applied to orthogonal cutting. Mach. Sci. Technol. 2010, 14, 323-343. [CrossRef]

19. Özel, T.; Esteves, A.; Davim, J.P. Neural network process modelling for turning of steel parts using conventional and wiper inserts. Int. J. Mater. Prod. Technol. 2009, 35, 246-258. [CrossRef]

20. Rajemi, M.F.; Mativenga, P.T.; Aramcharoen, A. Sustainable machining: Selection of optimum turning conditions based on minimum energy considerations. J. Clean. Prod. 2010, 18, 1059-1065. [CrossRef]

21. Hernández, L.W.; Pérez, R.; Dumitrescu, L.; Zambrano, P.C.; Guerrero, M.P. Efecto del volumen de metal cortado y de la velocidad de corte en el desgaste de la herramienta durante el torneado de alta velocidad del acero AISI 1045. Ing. Desarro. 2011, 29, 61-83.

22. Stachurski, W.; Midera, S.; Kruszyński, B. Determination of mathematical formulae for the cutting force Fc during the turning of C45 steel. Mech. Mech. Eng. 2012, 16, 73-79.

23. Hernández, L.W.; Pérez, R.; Zambrano, P.C.; Siller, H.R.; Toscano, H. Estudio del rendimiento del torneado de alta velocidad utilizando el coeficiente de dimensión volumétrica de la fuerza de corte resultante. Rev. Metal. 2013, 49, 161-172. [CrossRef]

24. Qasim, A.; Nisar, S.; Shah, A.; Khalid, M.S.; Sheikh, M.A. Optimization of process parameters for machining of AISI-1045 steel using Taguchi design and ANOVA. Simul. Model. Pract. Theory 2015, 59, 36-51. [CrossRef]

25. ANSI/ASME B94.55M. In Tool-Life Testing with Single-Point Turning Tools, 1st ed.; The American Society of Mechanical Engineers: New York, NY, USA, 1985.

26. Saï, W.B.; Zghal, A.; Ben, A.K. Carbide and ceramic tool life in high speed turning. Int. J. Veh. Des. 2005, 39, 140-153. [CrossRef]

27. Astakhov, V.P.; Davim, J.P. Tools (Geometry and Material) and Tool Wear. In Machining Fundamentals and Recent Advances, 1st ed.; Davim, J.P., Ed.; Springer-Verlag: London, UK, 2008; Volume 3, pp. 29-57, ISBN 978-1-84800-213-5. 
28. ASTM E140-97. In Standard Hardness Conversion Tables for Metals, 2nd ed.; American Society for Testing Materials: West Conshohocken, PA, USA, 1997.

29. Amón, I. Guía Metodológica Para la Selección de Técnicas de Depuración de Datos. Master's Thesis, Universidad Nacional de Colombia, Medellín, CO, USA, May 2010.

30. Dolinšek, S.; Šuštaršič, B.; Kopač, J. Wear mechanisms of cutting tools in high-speed cutting processes. Wear 2001, 250, 349-356. [CrossRef]

31. Kopač, J.; Soković, M. In Proceedings of the 16th International AMPT Conference, Dublin, Ireland, 3-6 August 1999.

32. Arsecularatne, J.A.; Zhang, L.C.; Montross, C. Wear and tool life of tungsten carbide, PCBN and PCD cutting tools. Int. J. Mach. Tools Manuf. 2006, 46, 482-491. [CrossRef]

33. Adesta, E.; Hazza, M.A.; Riza, M.; Agusman, D.; Rosehan, R. Tool life estimation model based on simulated flank wear during high speed hard turning. Eur. J. Sci. Res. 2010, 39, 265-278.

34. Bosheh, S.; Mativenga, P. White layer formation in hard turning of H13 tool steel at high cutting speeds using CBN tooling. Int. J. Mach. Tools Manuf. 2006, 46, 225-233. [CrossRef]

35. Liu, Z.K.; Ai, X.; Zhang, Z.; Wang, Z.T.; Wan, Y. Wear patterns and mechanisms of cutting tools in high-speed face milling. J. Mater. Process. Technol. 2002, 129, 222-226. [CrossRef]

36. Lin, Y.-J.; Agrawal, A.; Fang, Y. Wear progressions and tool life enhancement with AlCrN coated inserts in high-speed dry and wet steel lathing. Wear 2008, 264, 226-234. [CrossRef]

37. Gujarati, D.N.; Porter, D.C. Econometría, 5th ed.; McGraw-Hill/Irwin, Inc.: México city, Mexico, 2009; pp. 55-96, ISBN 978-607-15-0294-0.

38. Abukhshim, N.; Mativenga, P.; Sheikh, M. Heat generation and temperature prediction in metal cutting: A review and implications for high speed machining. Int. J. Mach. Tools Manuf. 2006, 46, 782-800. [CrossRef]

(C) 2018 by the authors. Licensee MDPI, Basel, Switzerland. This article is an open access article distributed under the terms and conditions of the Creative Commons Attribution (CC BY) license (http:/ / creativecommons.org/licenses/by/4.0/). 